\begin{tabular}{|c|l|}
\hline Title & $\begin{array}{l}\text { Y ield losses of soybean and maize by competition with interseeded cover crops and weeds in organic-based cropping } \\
\text { systems }\end{array}$ \\
\hline Author(s) & Uchino, H.; Iwama, K.; Jitsuyama, Y.; Y udate, T.; Nakamura, S. \\
\hline Citation & $\begin{array}{l}\text { Field Crops Research, 113(3), 342-351 } \\
\text { https://doi.org/10.1016/.fcr.2009.06.013 }\end{array}$ \\
\hline Issue Date & 2009-09-04 \\
\hline Doc URL & http://hdl.handle.net/2115/39223 \\
\hline Type & article(author version) \\
\hline File Information & FCR113_3_p342-351.pdf \\
\hline
\end{tabular}

Instructions for use 


\title{
Yield losses of soybean and maize by competition with interseeded cover crops and weeds in organic-based cropping systems
}

\author{
H. Uchino, K. Iwama*, Y. Jitsuyama, T. Yudate and S. Nakamura \\ Laboratory of Crop Science, Department of Botany and Agronomy, Graduate School of Agriculture, \\ Hokkaido University, Sapporo, 060-8589, Japan \\ ${ }^{*}$ Corresponding author. Tel.: +81-11-706-3878; fax: +81-11-706-3878. \\ E-mail address: iwama@res.agr.hokudai.ac.jp (K. Iwama)
}

\begin{abstract}
Weed management is a major issue in organic farming systems. Although interseeding cover crops is one alternative to herbicides, cover crops often suppress not only weeds but also main crops. Therefore, using cover crops for weed control without adverse effects on main crop growth is important. To verify the effect of cover crops on competition between main crops, cover crops and weeds in snowy-cold region, main crops soybean (Glycine max Merr.) in 2005 and maize (Zea mays L.) in 2006 were grown with cover crops winter rye (Secale cereale L.) and hairy vetch (Vicia villosa Roth), respectively. The cover crops were sown on three sowing dates: before main crop planting (Pre-MC), on the same date of main crop planting (Syn-MC) and after main crop planting (Post-MC). A plot without cover crops (Sole-MC) was used as a control. The dry weight (DW), vegetation cover ratio (VCR), vertical community structure and chlorophyll content were measured to estimate the competition between main crops, cover crops and weeds. Weed DW was suppressed significantly by sowing cover crops in both soybean and maize. This weed suppression was associated with the increase of VCR of main crops plus cover crops at the early
\end{abstract}


growth stage of main crops. Soil seed banks of dominant weed also became lower by sowing cover crops, implying the importance of proper weed management for suppressing weeds successively. In addition, the sowing dates of cover crops had large effects on main crops DW especially in maize, i.e., it was significantly lower in Pre-MC and Syn-MC than in Post-MC. Although the cover crop height was markedly shorter than the main crop height, the chlorophyll content of the main crops was significantly lower when cover crops were sown earlier. These results suggest that the growth inhibition of main crops by cover crops was partly caused by competition for nutrients between main crops and cover crops, and this growth inhibition was alleviated when cover crops were sown after the establishment of main crops. Consequently, soybean yield was the highest in Post-MC and decreased by $29 \%, 18 \%$ and $7 \%$ in Sole-MC, Pre-MC and Syn-MC, respectively, and maize yield was also the highest in Post-MC and decreased by $68 \%, 100 \%$ and $24 \%$ in Sole-MC, Pre-MC and Syn-MC, respectively. It was concluded that weeds could be controlled effectively by sowing cover crops after planting main crops in organic farming systems in snowy-cold region.

Keywords: interseeding; nutrients; light; leaf area index; vegetation cover ratio

\section{Abbreviations}

Sole-MC, only main crop without cover crop;

Pre-MC, cover crop preceding the main crop by 14 days (-14 DAS);

Syn-MC, cover crop synchronous with the main crop (0 DAS);

Post-MC, cover crop succeeding the main crop by 21 days (+21 DAS);

DAS, days after sowing the main crop;

VCR, vegetation cover ratio; 


\section{Introduction}

In organic farming systems, weeds are often recognized as the most serious threat to crop production. An alternative to herbicides is the use of cover crops, which can suppress the growth of weeds by competition for light (Teasdale and Mohler, 2000), soil moisture and nutrients (Barberi, 2002), and by producing allelopathic compounds (White et al., 1989; Reberg-Horton et al., 2005). Some reports, however, indicated that the growth of main crops was also sometimes suppressed because of competition for light (Hooks and Johnson, 2001), nutrients (Feil et al., 1997; Garibay et al., 1997) or water (Box et al., 1980) between cover crops and main crops.

To reduce the inhibition of main crops growth by cover crops, interseeding of cover crops (seeding into an established vegetation of main crops) is focused as a technique to avoid or decrease the competition between cover crops and main crops (Scott et al., 1987; Abdin et al., 1998, 2000). Some studies conducted the inclusion of interseeded cover crops into crop production systems in snowy-cold region (Hartl, 1989; Brainard et al., 2004), where most cover crops sown in the previous fall can not survive winter because of snow falling or can not produce enough biomass to suppress weeds. However, interseeded cover crops also sometimes reduce growth of main crops mainly because of direct competition between cover crops and main crops (Scott et al., 1987; DeHaan et al., 1994; Ateh and Doll, 1996). For instance, den Hollander et al. (2007) indicated that yield reduction of leek (Allium porrum L.) is mainly caused by competition for light between leek and interseeded clovers. We, therefore, need more information on cover crop characteristics (species, growth pattern) and cover crop management (sowing density, sowing date) for successful inclusion of cover crops in a weed management strategy (Barberi, 2002).

To quantify the effects of weeds on crop yields, the competitive-ability index (weedy yield / weed-free yield) was developed (Mohammadi, 2007). Other indexes were also used for measuring weed suppressive ability of crops (Hansen et al., 2008; Linares et al., 2008). These studies, however, focused 
mainly on the relationships between two plant species (i.e. between main crops and weeds or between cover crops and weeds). Since complex plant community is established in an interseeding crop system by main crops, cover crops and weeds, it is necessary to analyze the correlations of growth characteristics between them.

The purpose of this study is to clarify the competitive relationships between main crops, interseeded cover crops and weeds in organic farming system in snowy-cold region. The effect of sowing date of cover crops on the growth of main crops was investigated, focusing on competition for light and nutrients between main crops, cover crops and weeds. Main crops of soybean and maize were grown with cover crops of winter rye and hairy vetch, respectively. These two cover crops were chosen based on the result in a preliminary experiment, i.e., winter rye has a high WAS with a low plant height, and hairy vetch has the highest WAS among leguminous species (Uchino et al., 2005). The combinations of main crop and cover crop were based on a combination of legume and non-legume.

\section{Materials and Methods}

This study was done at the Field Science Center for the Northern Biosphere, Hokkaido University (Sapporo, Japan, 43 $04^{\prime} \mathrm{N}, 141^{\circ} 20^{\prime} \mathrm{E}$ ) in 2005 and 2006. The experimental site was upland field converted from paddy field and was fallowed with green manure of oat in 2004. The soil was Typic Udifluvent with a pH 6.5 and had $4.0 \%$ organic matter. Water table in the field was high (about $60 \mathrm{~cm}$ depth from the soil surface), because a water storage reservoir for the irrigation of paddy rice at the neighboring field is located near the present field.

In 2005 the main crop was soybean 'Toyomusume' and the cover crop was winter rye 'Fuyu-midori'. In 2006 the main crop was dent flint maize for silage '39H32' and the cover crop was hairy vetch 'Mameya'. The study was arranged as a randomized complete block design with four replications and each plot size was $3 \mathrm{~m}$ by $4 \mathrm{~m}$. Each plot consisted of five soybean rows $60 \mathrm{~cm}$ apart with $20 \mathrm{~cm}$ between 
plants in each row planted on 31st May 2005, and four maize rows planted $75 \mathrm{~cm}$ apart with $18 \mathrm{~cm}$ between plants in each row planted on 18th May 2006. Both cover crops were seeded at a planting density 400 grains $\mathrm{m}^{-2}$. We made four treatments of three sowing dates of cover crops ('Pre-Main Crop (MC)', 'Syn-MC' and 'Posh-MC') and without cover crops ('Sole-MC'): (a) 'Pre-MC’ treatment - cover crops were uniformly sown after rotary tilling 14 days before planting main crops. The main crops were seeded in a seeding furrow, dug with a hoe in the established cover crop community; (b) 'Syn-MC' treatment - cover crops and main crops were sown on the same day after rotary tilling; (c) 'Post-MC' treatment - cover crops were sown 21 days after sowing main crops (DAS). Weeds were all removed by intertillage and hand weeding just before sowing cover crops; (d) 'Sole-MC' treatment - cover crops were not sown and weeds grew freely during the growing season of main crops, which were planted after tillage at 0 DAS. Plots used for soybean in 2005 were used in exactly the same way for maize in 2006. The experiments were done without agricultural chemicals and synthetic fertilizers.

Soybean was irrigated at 9 and 22 DAS (total: $40 \mathrm{~mm}$ ) and maize was irrigated at 1 DAS (total: $16 \mathrm{~mm}$ ). A fully-ripened compost (total $\mathrm{N}$ content $0.73 \% \mathrm{w} / \mathrm{w}$ fresh weight) was incorporated into the soil at $50 \mathrm{tha}^{-1}$ for soybean and $40 \mathrm{tha}^{-1}$ for maize about 3 weeks before planting. Fermented organic fertilizer $\left(\mathrm{N} ; 5 \%, \mathrm{P}_{2} \mathrm{O}_{5} ; 6 \%, \mathrm{~K}_{2} \mathrm{O} ; 4 \%\right.$ ) at $0.5 \mathrm{t} \mathrm{ha}^{-1}$ for soybean and at $1.0 \mathrm{t} \mathrm{ha}^{-1}$ for maize was applied along the seeding furrow and about $5 \mathrm{~cm}$ below the main crop seeds at 0 DAS. Amount of organic fertilizers input is high in terms of nitrogen concentration. This is because not all organic matter is decomposed by soil microorganisms in the field condition for one year, and mineralization rate of organic matter depends strongly on temperature (Leiros et al., 1999), i.e., mineralization rate is accelerated by higher temperature. Since the present experimental site is located in the snow climate (Dfb) according to Koppen-Geiger climate classification (Kottek et al., 2006) and temperature during growing stage is low especially in early growth stage (Table 1), it is expected that nitrogen release ratio from organic matter is low for plant growth. We estimated that the efficiency index of the compost during growing period was less than $20 \%$ according 
to a model equation reported by Watanobe (2005). This index of the compost was used as a converted value of a compost input into a chemical fertilizer input equivalent in terms of nitrogen release.

Main crops, cover crops and weeds were sampled at the five growth stages of the main crops, including maturity (133 and 126 DAS for soybean and maize, respectively), and their dry weight (DW) were measured after drying for longer than 72 hours at $80{ }^{\circ} \mathrm{C}$. Cover crops and weeds were sampled from $0.60 \mathrm{~m}$ by $0.40 \mathrm{~m}$ (soybean) and $0.75 \mathrm{~m}$ by $0.36 \mathrm{~m}$ (maize) quadrates that were established parallel to the main crop rows. The number of weeds was also counted at each sampling time. At the maximum plant height stage of the main crops (76 DAS for soybean and 77 DAS for maize), the vertical community structure was determined by using the stratified clip method (Monsi and Saeki, 1953). The leaf areas of main crops, cover crops and weeds were measured at layer 0-20, 20-40, 40-60, 60-80, 80-100 and 100-120 $\mathrm{cm}$ for soybean, and 0-50, 50-100, 100-150, 150-200 and 200-250 cm for maize by using an automatic area meter (AAM-9, Hayashi Denko, Tokyo, Japan). Canopy photosynthetically active radiation (PAR) transmittance was measured at $0,20,40,60,80$ and $100 \mathrm{~cm}$ above ground for soybean and at $0,50,100$, 150 and $200 \mathrm{~cm}$ above ground for maize by using a PAR line sensor (LI-191, LI-COR, Lincoln, NE, USA). The chlorophyll content of the uppermost fully expanded leaves of 4 plants was estimated at almost weekly intervals by using a chlorophyll content meter (SPAD-502, Minolta, Tokyo, Japan). SPAD value was considered to be one indicator for estimating the competition for nitrogen (Shafagh-Kolvanagh et al., 2008). The vegetation cover ratio (VCR) of main crops, cover crops and weeds was recorded at weekly intervals until canopy closure (45 DAS in soybean and 56 DAS in maize). Near-infrared images were taken from 1-3.5 m above ground by using a cover ratio camera (Kimura Oyokogei, Saitama, Japan). Cover crops or weeds were cut off from the images by using an image processing program (Adobe Photoshop Elements version 1.0J, Adobe Systems, CA, USA), and each VCR of main crops, cover crops and weeds was estimated separately by using software (Kimura Oyokogei, Saitama, Japan) after image binarization. The measurement range of the VCR was $80 \times 120 \mathrm{~cm}$ for soybean and $90 \times 75 \mathrm{~cm}$ for maize. 
Soil seed banks (surviving seed number per unit area) were collected in April 2006 before the application of the compost. At each plot, three soil cores (diameter $5 \mathrm{~cm}$, depth $5.1 \mathrm{~cm}$ ) were taken randomly and were pooled. The seed banks were assessed by using a modified seedling emergence method (Ter Heerdt et al., 1996). The seeds were concentrated by washing the soil through a fine sieve (mesh width $0.35 \mathrm{~mm}$ ), were spread out in a pot (diameter $9 \mathrm{~cm}$, depth $7.5 \mathrm{~cm}$ ) filled with steam-sterile potting soil topped with a thin layer of sterilized white perlite and filter paper (diameter $11 \mathrm{~cm}$ ), and were placed in a glasshouse for 16 weeks. The daily average temperature of glasshouse during the incubation was from 9.6 to $31.2^{\circ} \mathrm{C}$. Seedlings were counted and removed as soon as they could be identified.

Meteorological data of daily mean air temperature at $150 \mathrm{~cm}$ high, solar radiation and precipitation were obtained from the Sapporo District Meteorological Observatory (43 $04^{\prime} \mathrm{N}, 141^{\circ} 20^{\prime} \mathrm{E}$ ). The accumulated effective temperature for dominant weed was calculated as a sum of 'dairy average temperature minus lower threshold temperature of the dominant weed for germination (Wiese and Binning, 1987)'. Starting dates of calculating the accumulated effective temperature varied among treatments because of different timings of weed control management (rotary tilling and weeding), i.e., the effective temperature was began to accumulate from 14 days before planting main crops in Pre-MC, from 0 DAS in Syn-MC and Sole-MC and from 21 DAS in Post-MC.

Statistical analysis was done by using the SPSS software (version 14.0J, SPSS Japan, Tokyo, Japan). The least significant difference (LSD) test was used to separate differences between treatment means if a one-way analysis of variance for each year indicated significance at $5 \%$ levels of probability.

3. Results

3.1. Experiment in 2005 (Main crop: soybean, Cover crop: winter rye)

The mean value of the daily average temperature during growing season was slightly higher $(0.7$ 
${ }^{\circ} \mathrm{C}$ ) than mean value from 1971 to 2006 (Table 1). The temperature during first two weeks from sowing cover crop increased as sowing date was later (Pre-MC, $13.1^{\circ} \mathrm{C}$; Syn-MC, $16.7^{\circ} \mathrm{C}$; Post-MC, $19.7^{\circ} \mathrm{C}$ ). Solar radiation and precipitation did not differ considerably compared to mean values of 36 years.

Weed number did not differed significantly between treatments during growing season (Fig. 1a). Weed DW was significantly and markedly higher in Sole-MC than in the other treatments during growing season (Fig. 1 b), indicating the significant suppression of weed growth by sowing cover crops. In addition, weed DW was also significantly higher in Syn-MC than in Post-MC at 55 DAS.

The DW of soybean was significantly higher in Post-MC than in Pre-MC throughout the growing season (Fig. 2 a). Although the DW of soybean increased from 76 to 133 DAS in Pre-MC and Syn-MC, it did not increase in Sole-MC, resulting in the lowest DW in Sole-MC at maturity. Consequently, grain yield of soybean was the highest in Post-MC and decreased by $29 \%, 18 \%$ and $7 \%$ in Sole-MC, Pre-MC and Syn-MC, respectively (Table 2). It was mainly caused by lower pod number per plant.

The DW of winter rye was higher as the sowing date of winter rye was earlier (Fig. 2 b). Regardless of the sowing date, the DW of winter rye reached a peak at the middle growth stage of soybean (55 DAS) and thereafter, decreased to $0 \mathrm{~g} \mathrm{~m}^{-2}$ at the maturity stage of soybean. Almost all plants of winter rye were dead completely and decayed partially at 133 DAS.

Total DW, which was calculated by a sum of DW of soybean and weeds at harvest stage of soybean, was significantly higher in Sole-MC than in the other treatments because of a substantial weed DW in Sole-MC (Fig. 3a). The percentage of soybean DW to total DW was considerably higher in Pre-MC, Syn-MC and Post-MC than in Sole-MC, indicating that soybean could accumulate larger biomass compared to weeds by sowing winter rye.

To estimate the aboveground competition between soybean, winter rye and weeds, their VCR were shown in Fig. 4a-d. The VCR of soybean plus winter rye differed considerably among all treatments. In Pre-MC, in which the soil surface began to be covered with pre-sown winter rye before seeding soybean, 
the VCR of winter rye was the highest at 0 DAS and the VCR of weeds was relatively low until canopy closure of 45 DAS. In Post-MC, the VCR of soybean plus winter rye increased sharply after removing weeds and sowing winter rye (21DAS), and resulted in the lowest VCR of weeds. When comparing the VCR of soybean alone, it was lower when winter rye was sown earlier, i.e., the VCR was markedly low in Pre-MC and relatively low in Syn-MC compared with Post-MC. The VCR of soybean and the total VCR (sum of VCR of soybean, winter rye and weeds) were almost the same between Syn-MC and Sole-MC, but the VCR of weeds differed greatly between these two treatments: it was much higher in Sole-MC than in Syn-MC. This result indicates that the winter rye competed with weeds from early growth stage, i.e., the gap area (open space surrounding vegetation), which could not be covered with soybean alone, was covered competitively by winter rye and weeds in Syn-MC but was exclusively by weeds alone in Sole-MC.

In the present study, the timings of weed control managements were varied between treatments. Therefore, the VCR of soybean plus winter rye was re-analyzed on the basis of the accumulated effective temperature for a dominant weed, redroot pigweed (Fig. 5a). Lower threshold temperature of redroot pigweed for germination was defined at $10{ }^{\circ} \mathrm{C}$ according to the study by Wiese and Binning (1987). The VCR of soybean plus winter rye was the highest in Post-MC even at low accumulated sufficient temperature. This is because weeds were removed by hand at 21 DAS and soybean already covered soil surface partially at that time, and winter rye also covered the soil additionally thereafter.

Additionally we investigated the vertical community structure at the maximum plant height stage of soybean to estimate the aboveground competition between soybean, winter rye and weeds (Fig. 6a-d). Weeds grew taller and the LAI of weeds was markedly higher in Sole-MC than in the other treatments: the plant height of weeds exceeded that of the main crop in Sole-MC. Contrary to the weeds, the plant height of winter rye was much lower than that of soybean. Since winter rye has a high degree of winter habit, it could not elongate stem without vernalization. In addition, the LAI of soybean in Pre-MC and Syn-MC were significantly lower than Post-MC, and were also slightly lower than Sole-MC. These results imply that 
winter rye suppressed the growth of soybean because of the factors other than light competition.

For estimating the nutrients competition of soybean with winter rye and weeds, SPAD value of soybean, which reflected the nitrogen concentration in leaves, is shown in Fig. 7a. The SPAD value in Pre-MC was significantly lower than in Post-MC until 72 DAS, and was also lower than in Syn-MC until 51 DAS. This result indicates that winter rye competed more severely with soybean for nitrogen when winter rye was sown earlier.

\subsection{Experiment in 2006 (Main crop: maize, Cover crop: hairy vetch)}

Since the daily average temperature in June and the temperature increase from May to June were lower compared to 2005 and 36-years mean value (Table 1), the temperature during first two weeks from sowing cover crop did not differed markedly among three sowing dates (Pre-MC, $13.2{ }^{\circ} \mathrm{C}$; Syn-MC, $13.8^{\circ} \mathrm{C}$; Post-MC, $13.9^{\circ} \mathrm{C}$ ). The total precipitation during growing season decreased by more than $100 \mathrm{~mm}$ compared to 2005 and 36-years mean value. In particular, the precipitation in August and September were considerably lower, but no inhibition of crop growth by drought was observed. High soil water retention capacity in the present field, which was converted from paddy field, is one reason of this drought avoidance.

Weed number was significantly higher in Sole-MC than in the other treatments throughout growing season (Fig. 1c). Weed DW was significantly the highest in Sole-MC throughout growing season, and was higher in Syn-MC than in Pre-MC and Post-MC at 54 and 77 DAS (Fig. 1d).

When comparing weed growth in Sole-MC and Syn-MC between experiments in 2005 (soybean) and in 2006 (maize), weed number was markedly higher in 2006 than in 2005 throughout the growing season, and weed DW was also higher in 2006 than in 2005 at the early growth stage of main crops. In particular, weed number at first sampling was 15 times higher in 2006 than in 2005 in Sole-MC, and four times in Syn-MC. 
Table 3 shows the seedling number of annual weeds germinated from soil seed banks sampled before the experiment in 2006. Annual broadleaf species, such as redroot pigweed (Amaranthus retroflexus L.), common purslane (Portulaca oleracea L.) and tufted knotweed (Polygonum longisetum De Bruyn), and several annual grass species, such as barnyardgrass (Echinochloa crus-galli Beauv.), southern crabgrass (Digitaria adscendens Henr.) and annual bluegrass (Poa annua L.), were in the soil seed banks. Among them, redroot pigweed grew continuously until the late growth stage of the main crops, and mostly dominated in the field of the present study. Although common purslane showed the highest seedling number (data not shown) in the seed banks, it ended its life early in the field.

The seedling number of all annual weeds from soil seed banks was significantly higher in Sole-MC than in Pre-MC and Post-MC, and the seedling number of redroot pigweed was significantly higher in Sole-MC than in the other treatments. Although the seedling number of all annual weeds and redroot pigweed did not differ significantly among three sowing dates of cover crops, they tended to be lower in Post-MC than in Pre-MC and Syn-MC. The seedling number of redroot pigweed showed a significant correlation with weed DW at the maturity stage for soybean in $2005\left(\mathrm{r}=0.965^{*}, \mathrm{n}=4\right)$. In addition, the seedling number of all annual weeds correlated significantly with the weed number at 40 DAS for maize in $2006\left(r=0.988^{* *}, n=4\right)$. These correlations indicate that higher weed number and weed DW in Sole-MC and Syn-MC for maize in 2006 than for soybean in 2005 were caused by the vigorous growth and large amount of seed production of weeds in these treatments for soybean in 2005.

The DW of maize was significantly the highest in Post-MC, and then Syn-MC and Sole-MC (Fig. 2c). In Pre-MC, all maize plants died and the DW of maize became zero at 77 DAS. The DW of maize in Sole-MC and Syn-MC were almost the same until 77 DAS, but thereafter it increased considerably in Syn-MC but not as much in Sole-MC. Consequently, the grain yield of maize was the highest in Post-MC, in which the 1000-grain weight was significantly highest (Table 2). Compared with Post-MC, 68 \%, $100 \%$ and $24 \%$ yield reduction were noted in Sole-MC, Pre-MC and Syn-MC respectively. 
The DW of hairy vetch reached a peak at 54 DAS and then decreased to $0 \mathrm{~g} \mathrm{~m}^{-2}$ at the maturity stage of maize in all treatments (Fig. 2d). The growth of hairy vetch was the most vigorous in Pre-MC, and then in Syn-MC and Post-MC.

Total DW, which was calculated by a sum of DW of maize and weeds at harvest stage of maize, was significantly the highest in Post-MC (Fig. 3b). In Pre-MC, total DW was the lowest. Early senescence of maize is one reason causing this low total DW. In addition, hairy vetch was also dead and decayed until the end of experiment (Fig. 2d). We did not sample the dead plants in the present study, causing the lowest total DW in Pre-MC. As in the experiment for soybean in 2005, the percentage of maize DW to total DW was the highest in Post-MC.

Until canopy closure of 56 DAS, the VCR of maize plus hairy vetch was much higher than the VCR of weeds in Pre-MC and Post-MC (Fig. 4e-h). However, the VCR of maize in Pre-MC increased little just after seeding, and finally all maize plants died due to a vigorous growth of hairy vetch. The VCR of maize and the total VCR (sum of VCR of maize, hairy vetch and weeds) were almost the same between Sole-MC and Syn-MC, but the VCR of weeds was much higher in Sole-MC than in Syn-MC. This result indicates that the hairy vetch competed with weeds from early growth stage of maize, and open area, which could not be covered with maize alone, was covered competitively by hairy vetch and weeds in Syn-MC but was by weeds alone in Sole-MC.

The VCR of maize plus hairy vetch on the accumulated effective temperature basis was slightly higher in Pre-MC and Post-MC than in Syn-MC at higher than $150{ }^{\circ} \mathrm{C} \cdot$ day of accumulated effective temperature (Fig. 5b).

In vertical community structure at the maximum plant height stage of maize, the plant height and LAI of weeds were considerably higher in Sole-MC than in the other treatments (Fig. 6e-h). In Pre-MC, the LAI of weeds was the lowest, because the vigorous growth of hairy vetch suppressed not only maize but also weeds. Although hairy vetch generally produced long vines that entwine around other plants, the vines 
rarely entwined around maize except for Pre-MC, and the plant height and the LAI of hairy vetch were much lower than those of maize in Syn-MC and Post-MC. In addition, the LAI of maize was significantly higher in Post-MC than in Syn-MC and Sole-MC. These results imply that hairy vetch and weeds suppressed the growth of maize because of the factors other than light competition.

The SPAD value of maize was significantly the highest in Post-MC throughout the growing season (Fig. 7b). On the other hand, the SPAD value in Pre-MC was markedly the lowest at 54 DAS and then could not be measured after 64 DAS because the maize plants died. In addition, although the SPAD value in Sole-MC and Syn-MC were significantly lower than that in Post-MC at 54 DAS, the SPAD value increased only in Syn-MC and there were no significant differences between Syn-MC and Post-MC after 79 DAS. These results indicate that the maize competed with hairy vetch and weeds for nitrogen, and that this competition was minimized when the hairy vetch was sown later.

\section{Discussion}

4.1. Effects of previous weed management on soil seed banks and subsequent weed growth

The difference between treatments in weed number was much larger for maize in 2006 than for soybean in 2005. It is considered to be due to the differences in soil seed banks between two years. Rahman et al. (2006) reported that there was a strong linear correlation between the soil seed banks and the emerged seedling number in the field for most weed species. Buhler (1999) also reported that weed management practices greatly affect soil seed banks.

4.2. Competitions for light and nutrients between main crops, cover crops and weeds

When two or more plants overlapped in the same area, they generally competed with each other for environmental resources (Zimdahl, 2004). In the present study, main crops, cover crops and weeds 
competed each other for environmental resources at various degrees. These competitions resulted in the difference of dry matter production of main crops between treatments (Fig. 2). We evaluated the competition for light by VCR (Figs. 4, 5) and vertical community structure (Fig. 6), and the competition for nutrients by leaf chlorophyll contents (Fig. 7).

\subsubsection{Competition for light}

In the present study, although we used different cover crops winter rye in 2005 and hairy vetch in 2006, cover crop DW decreased and main crop DW increased after the middle growth stage of the main crops in the treatments with sowing cover crops in both years (Fig. 2). It is due to the reason that the plant height of cover crops was much lower than that of main crops (Fig. 6), and thus, these cover crops could not obtain enough light to grow because most of solar radiation was absorbed by main crops, which had higher plant height and larger leaf area.

In contrast with cover crops, weeds reached over $100 \mathrm{~cm}$ high and expanded more leaves at upper layer in Sole-MC in both years (Fig. 6). Weeds with high plant height absorbed light largely at the upper layer and decreased solar radiation for main crops, causing the vigorous growth of weeds even after the maximum plant height stage of the main crops and the inhibition of successive dry matter production of main crops in Sole-MC (Fig. 2).

The competition for light was also occurred between cover crops and weeds, particularly at the early growth stage (Fig. 4). Since small plants are more sensitive to environmental stresses (Harbur and Owen, 2004), it is considered that the competition with cover crops inflicted more crucial damage to weed growth at seedling stage compared to later growth stage. The suppression of weeds at the early growth stage was important for successful weed control by cover crops (Uchino et al., 2005).

Bilalis et al. (2003) indicated that there was a significant and negative correlation between percentage of soil cover by crop residue and weed DW. Peachy et al. (1999) and Teasdale and Mohler 
(2000) also reported that the degree of weed suppression depended on soil coverage of vegetation. In the present study, as shown in Fig. 8, there was a significant and inverse correlation between the VCR and weed DW for both main crops, i.e., weed DW decreased as the VCR of main crops plus cover crops increased. Kropff and Spitters (1991) developed a simple and precise model to predict crop yield loss due to weed competition by using the relative leaf area of weeds at the early growth stage. Storkey et al. (2003) also developed an empirical model of crop and weed competition by using a parameter of relative weed green area (weed green area/weed + crop green area). The present study also implies that there is the potential to predict weed growth and yield loss of main crops according to VCR at the early growth stage (Fig. 8). Since the VCR was measured easily, quickly and non-destructively by just taking pictures with a cover ratio camera, the measurement of VCR over years and/or locations are suitable to develop a precise prediction model in a complex plant community of main crops, cover crops and weeds in organic farming systems.

\subsubsection{Competition for nutrients}

It is reported that nitrogen availability is the most limiting factor of crop yield in organic farming, because of insufficient decay of added organic matter or immobilization of nitrogen by soil microorganisms (Clark et al., 1999). In the present study, the comparison of SPAD value between treatments (Fig. 7) indicated that the severe competition for nitrogen was occurred between maize and weeds, and this competition was alleviated by sowing cover crops at the same time or after the establishment of maize. On the contrary, the SPAD value of soybean showed lesser differences between the treatments than those of maize, indicating the limited competition for nitrogen between soybean and weeds, and also between soybean and cover crops. A possible reason of the difference between maize and soybean in competition for nitrogen is that the main crops in the present study were a legume (soybean) or a non-legume (maize). Generally, legume plants, such as soybean, fix atmospheric nitrogen, and therefore they can grow under 
lower nitrogen conditions compared with non-legume plants, such as maize. In the present study, although the weed DW in Sole-MC showed similar increase in soybean and maize (Fig. 1), the SPAD value for Sole-MC were suppressed longer and more severely for maize than for soybean (Fig. 7), implying that maize is more sensitive to competition for nitrogen than soybean, which can recover from nitrogen deficiency by its nitrogen fixation.

In addition, the date of the increase in SPAD value for maize in Syn-MC (Fig. 7) roughly coincided with the date of decrease in cover crop DW (Fig. 2), suggesting that the competition for nitrogen between main crops and cover crops was alleviated when growth vigor of cover crops weakened. Therefore, early senescence of cover crops will be important to alleviate competition for nitrogen with maize at the late growth stage.

\subsubsection{Other factors affecting the competition}

The daily average temperature in June was lower in 2006 compared to 2005 and 36-years average (Table 1). Since hairy vetch is inherently winter annual legume (Sustainable Agriculture Network, 2007), low temperature during early growth stage in 2006 may cause positive effects on hairy vetch growth. On the other hand, since maize is summer annual crop, low temperature in 2006 may cause negative effects on maize growth. In fact, maize growth at the early growth stage was severely suppressed by the vigorous growth of hairy vetch in Pre-MC and Syn-MC (Figs. 2, 4). Brainard and Bellinder (2004) indicated that lower initial temperature favored the growth and competitive ability of winter annual cover crop. The present result indicates that the combination of main crop species and cover crop species in relation to the adaptability for low temperature will be important in snowy-cold region.

\section{Conclusions}

The growth of weeds could be suppressed by sowing cover crops, and the yield reduction of the 
main crops was alleviated. However, sowing date of cover crops was important for achieving high yield of main crops, especially in maize. DW and yield of main crops were the highest when cover crops were sown after the establishment of main crops. Soil seed banks also became lower by sowing cover crops, implying the importance of proper weed management for long-term weed suppression in organic farming system. Since the treatment with a complete weed control was not included in the present study, further experiments should be done for evaluating the benefits of late-sown cover crops in our region more accurately.

Acknowledgments

We thank Mr. S. Ichikawa of the Field Science Center for the Northern Biosphere, Hokkaido University, for the experimental management.

\section{References}

Abdin, O., Coulman, B.E., Cloutier, D., Faris, M.A., Zhou, X.M., Smith, D.L., 1998. Yield and yield components of corn interseeded with cover crops. Agron. J. 90, 63-68.

Abdin, O.A., Zhou, X.M., Cloutier, D., Coulman, D.C., Faris, M.A., Smith, D.L., 2000. Cover crops and interrow tillage for weed control in short season maize (Zea mays). Eur. J. Agron. 12, 93-102.

Ateh, C.M., Doll, J.D., 1996. Spring-planted winter rye (Secale cereale) as a living mulch to control weeds in soybean (Glycine max). Weed Technol. 10, 347-353.

Barberi, P., 2002. Weed management in organic agriculture: are we addressing the right issues? Weed Research 42, 177-193.

Box Jr., J.E., Wilkinson, S.R., Dawson, R.N., Kozachyn, J., 1980. Soil water effects on no-till corn production in strip and completely killed mulches. Agron. J. 72, 797-802.

Bilalis, D., Sidiras, N., Economou, G., Vakali, C., 2003. Effect of Different Levels of Wheat Straw Soil Surface Coverage on Weed Flora in Vicia faba Crops. J. Agron. Crop Sci. 189, 233-241. 
Brainard, D.C., Bellinder, R.R., 2004. Weed suppression in a broccoli-winter rye intercropping system. Weed Sci. 52, 281-290.

Brainard, D.C., Bellinder, R.R., Miller, A.J., 2004. Cultivation and interseeding for weed control in transplanted cabbage. Weed Technol. 18, 704-710.

Buhler, D.D., 1999. Weed population responses to weed control practices. I. Seed bank, weed populations, and crop yields. Weed Sci. 47, 416-422.

Clark, M.S., Horwath, W.R., Shennan, C., Scow, K.M., Lantni, W.T., Ferris, H., 1999. Nitrogen, weeds and water as yield-limiting factors in conventional, low-input, and organic tomato systems. Agric. Ecosyst. Environ. 73, 257-270.

DeHaan, R.L., Wyse, D.L., Ehlke, N.J., Maxwell, B.D., Putnam, D.H., 1994. Simulation of Spring-Seeded Smother Plants for Weed-Control in Corn (Zea-Mays). Weed Sci. 42, 35-43.

den Hollander, N.G., Bastiaans, L., Kropff, M.J., 2007. Clover as a cover crop for weed suppression in an intercropping design - II. Competitive ability of several clover species. Eur. J. Agron. 26, $104-112$.

Feil, B., S. V. Garibay, H. U. Ammon, P. Stamp, 1997. Maize production in a grass mulch system-seasonal patterns of indicators of the nitrogen status of maize. Eur. J. Agron. 7, 171.

Garibay, S.V., Stamp, P., Ammon, H.U., Feil, B., 1997. Yield and quality components of silage maize in killed and live cover crop sods. Eur. J. Agron. 6, 179-190.

Hansen, P.K., Kristensen, K., Willas, J., 2008. A weed suppressive index for spring barley (Hordeum vulgare) varieties. Weed Res. 48, 225-236.

Harbur, M.M., Owen, M.D.K., 2004. Response of three annual weeds to corn population density and nitrogen fertilization timing. Weed Sci. 52, 845-853.

Hartl, W., 1989. Influence of Undersown Clovers on Weeds and on the Yield of Winter-Wheat in Organic Farming. Agric. Ecosyst. Environ. 27, 389-396. 
Hooks, C.R.R., Johnson, M.W., 2001. Broccoli growth parameters and level of head infestations in simple and mixed plantings: Impact of increased flora diversification. Ann. Appl. Biol. 138, 269-280.

Kottek, M., Grieser, J., Beck, C., Rudolf, B., Rubel, F., 2006. World map of the Koppen-Geiger climate classification updated, Meteorol. Zeitschr., 15, 259-263.

Kropff, M.J., Spitters, C.J.T., 1991. A Simple-Model of Crop Loss by Weed Competition from Early Observations on Relative Leaf-Area of the Weeds. Weed Res. 31, 97-105.

Leiros, M.C., Trasar-Cepeda, C., Seoane, S., Gil-Sotres, F., 1999. Dependence of mineralization of soil organic matter on temperature and moisture. Soil Biol. Biochem. 31, 327-335.

Linares, J., Scholberg, J., Boote, K., Chase, C.A., Ferguson, J.J., McSorley, R., 2008. Use of the cover crop weed index to evaluate weed suppression by cover crops in organic citrus orchards. Hortscience 43, 27-34.

Mohammadi, G.R., 2007. Growth parameters enhancing the competitive ability of corn (Zea mays L.) against weeds. Weed Biol. Manag. 7, 232-236.

Monsi, M., Saeki, T., 1953. Über den Lichtfactor in den Pflanzengesellschaften und seine Bedeutung für die Stoffproduktion. Japanese Journal of Botany 14, 22-52.

Peachy, R.E., Luna, R., Dick, R., Sattell, R., 1999. Cover Crop Weed Suppression in Annual Rotations. Oregon Cover Crops, Oregon State University Extension Service.

Rahman, A., James, T.K., Grbavac, N., 2006. Correlation between the soil seed bank and weed populations in maize fields. Weed Biol. Manag. 6, 228-234.

Reberg-Horton, S.C., Burton, J.D., Danehower, D.A., Ma, G.Y., Monks, D.W., Murphy, J.P., Ranells, N.N., Williamson, J.D., Creamer, N.G., 2005. Changes over time in the allelochemical content of ten cultivars of rye (Secale cereale L.). J. Chem. Ecol. 31, 179-193.

Scott, T.W., Pleasant, J.M., Burt, R.F., Otis, D.J., 1987. Contributions of Ground Cover, Dry-Matter, and Nitrogen from Intercrops and Cover Crops in a Corn Polyculture System. Agron. J. 79, 
792-798.

Shafagh-Kolvanagh, J., Zehtab-Salmasi, S., Javanshir, A., Moghaddam, M., Nasab, A.D.M., 2008. Effects of nitrogen and duration of weed interference on grain yield and SPAD (chlorophyll) value of soybean (Glycine max (L.) Merrill.). J. Food Agric. Environ. 6, 368-373.

Storkey, J., Cussans, J.W., Lutman, P.J.W., Blair, A.M., 2003. The combination of a simulation and an empirical model of crop/weed competition to estimate yield loss from Alopecurus myosuroides in winter wheat. Field Crops Res. 84, 291-301.

Sustainable Agriculture Network, 2007. Managing cover crops profitably, 3rd Edition. Sustainable Agriculture Network Handbook Series, Book 9. Sustainable Agriculture Research and Education, Washington, DC.

Teasdale, J.R., Mohler, C.L., 2000. The quantitative relationship between weed emergence and the physical properties of mulches. Weed Sci. 48, 385-392.

Ter Heerdt, G.N.J., Verweij, G.L., Bekker, R.M., Bakker, J.P., 1996. An Improved Method for Seed-Bank Analysis: Seedling Emergence After Removing the Soil by Sieving. Funct. Ecol. 10, 144-151.

Uchino, H., Iwama, K., Terauchi, T., Jitsuyama, Y., 2005. Weed control by cover crops under organic farming of maize, soybean and potato. http://www.regional.org.au/au/allelopathy/2005/2/1/2494_uchinoh.htm

Watanobe, K., 2005. Efficient use of animal manure as a fertilizer for forage production. Research at Hokkaido prefectural research centers. In: Global perspective on resource recycling for sustainable agriculture: the 2005 Obihiro Asia and the Pacific Seminar on Education for Rural Development. The organizing committee of OASERD, Obihiro University of Agriculture and Veterinary Medicine, Dairy Japan, Tokyo, pp. 101-104.

White, R.H., Worsham, A.D., Blum, U., 1989. Allelopathic potential of legume debris and aqueous extracts. Weed Sci. 37, 674-679. 
Wiese, A.M., Binning, L.K., 1987. Calculating the Threshold Temperature of Development for Weeds. Weed Sci. 35, 177-179.

Zimdahl, R.L., 2004. Weed-Crop Competition -A Review, Second Edition, Blackwell publishing, IOWA, USA. 
Table 1

Mean of daily average air temperature, total solar radiation and precipitation of each month during growing season in 2005 and 2006.

\begin{tabular}{|c|c|c|c|c|c|c|c|c|c|}
\hline \multirow[t]{2}{*}{ Month } & \multicolumn{3}{|c|}{$\begin{array}{c}\text { Air temperature } \\
\left({ }^{\circ} \mathrm{C}\right)\end{array}$} & \multicolumn{3}{|c|}{$\begin{array}{c}\text { Solar radiation } \\
\left(\mathrm{MJ} \mathrm{m}^{-2}\right)\end{array}$} & \multicolumn{3}{|c|}{$\begin{array}{l}\text { Precipitation } \\
\text { (mm) }\end{array}$} \\
\hline & 2005 & 2006 & $1971-2006$ & 2005 & 2006 & $1971-2006$ & 2005 & 2006 & $1971-2006$ \\
\hline May & 10.7 & 12.9 & 12.2 & 549 & 601 & 550 & 62 & 45 & 53 \\
\hline June & 18.3 & 15.7 & 16.4 & 606 & 516 & 557 & 51 & 77 & 53 \\
\hline July & 20.1 & 20.6 & 20.4 & 527 & 608 & 528 & 119 & 106 & 72 \\
\hline August & 23.5 & 24.3 & 22.0 & 536 & 577 & 478 & 114 & 36 & 131 \\
\hline September & 18.8 & 18.5 & 17.7 & 393 & 444 & 385 & 126 & 58 & 135 \\
\hline October & 13.2 & 11.7 & 11.4 & 329 & 322 & 293 & 72 & 91 & 120 \\
\hline Mean or Total & 17.4 & 17.3 & 16.7 & 2940 & 3068 & 2791 & 544 & 412 & 565 \\
\hline
\end{tabular}


Table 2

Grain yield and yield components of soybean in 2005 and maize in 2006.

\begin{tabular}{|c|c|c|c|c|c|c|c|c|c|}
\hline \multirow[b]{2}{*}{ Treatment } & \multicolumn{4}{|c|}{ Soybean } & \multicolumn{5}{|c|}{ Maize } \\
\hline & $\begin{array}{c}\text { Grain } \\
\text { yield } \\
\text { (kg / ha) }\end{array}$ & $\begin{array}{c}\text { Pod no. } \\
\text { per plant }\end{array}$ & $\begin{array}{c}\text { Grain no. } \\
\text { per pod }\end{array}$ & $\begin{array}{l}\text { 1000-grain } \\
\text { weight } \\
\text { (g) }\end{array}$ & $\begin{array}{c}\text { Grain } \\
\text { yield } \\
\text { (kg / ha) }\end{array}$ & $\begin{array}{c}\text { Ear no. } \\
\text { per plant }\end{array}$ & $\begin{array}{l}\text { Row no. } \\
\text { per ear }\end{array}$ & $\begin{array}{c}\text { Grain no. } \\
\text { per row }\end{array}$ & $\begin{array}{c}\text { 1000-grain } \\
\text { weight } \\
\text { (g) }\end{array}$ \\
\hline Sole-MC & 3118 & 31.8 & 1.72 & 341 & 3106 & 1.0 & 14.4 & 36.7 & 218 \\
\hline Pre-MC & 3606 & 35.2 & 1.86 & 330 & $0^{a}$ & - & - & - & - \\
\hline Syn-MC & 4113 & 38.9 & 1.84 & 346 & 7393 & 1.0 & 15.4 & 40.4 & 215 \\
\hline Post-MC & 4403 & 45.0 & 1.75 & 335 & 9674 & 1.0 & 13.9 & 39.5 & 274 \\
\hline $\operatorname{LSD}(0.05)$ & 840 & 7.0 & 0.06 & NS & 1660 & NS & 1.1 & 2.4 & 40 \\
\hline
\end{tabular}

${ }^{\mathrm{a}}$ All plants died before maturity of maize. 
Table 3

Seedling number (plant $\mathrm{m}^{-2}$ ) of all annual weeds and redroot pigweed germinated from the soil seed banks before maize experiment in 2006.

\begin{tabular}{ccc}
\hline Treatment & $\begin{array}{c}\text { All annual } \\
\text { species }^{\mathrm{a}}\end{array}$ & $\begin{array}{c}\text { Redroot } \\
\text { pigweed }^{\mathrm{b}}\end{array}$ \\
\hline Sole-MC & 60083 & 4583 \\
Pre-MC & 6208 & 1583 \\
Syn-MC & 22292 & 1417 \\
Post-MC & 4291 & 417 \\
& & \\
LSD (0.05) & 49264 & 2715 \\
\hline
\end{tabular}

a All annual species include broadleaf species, such as redroot pigweed (Amaranthus retroflexus L.), common purslane (Portulaca oleracea L.) and tufted knotweed (Polygonum longisetum De Bruyn), and several grass species, such as barnyardgrass (Echinochloa crus-galli Beauv.), southern crabgrass (Digitaria adscendens Henr.) and annual bluegrass (Poa annua L.).

${ }^{\mathrm{b}}$ Dominant weed in the present field. 
Figure captions

Fig. 1 Weed number (a, c) and weed dry weight (b, d) in the experiment for soybean in 2005 (a, b) and for maize in 2006 (c, d).

$\diamond$ Sole-MC; $\bigcirc$ Pre-MC; $\triangle$ Syn-MC; $\square$ Post-MC. Vertical bars indicate LSD values $(\mathrm{P}=0.05)$ for the comparison between treatments.

Fig. 2 Dry weight (DW) of soybean (a) and winter rye (b) in 2005, and maize (c) and hairy vetch (d) in 2006.

$\supset$ Sole-MC; $\bigcirc$ Pre-MC; $\triangle$ Syn-MC; $\square$ Post-MC. Vertical bars indicate LSD values $(\mathrm{P}=0.05)$ for the comparison between treatments.

Fig. 3 Total dry weight (DW) of main crops and weeds at the harvest stage of soybean in 2005 (a) and maize in 2006 (b).

White bar, main crops; Black bar, weeds. Cover crops were dead completely at the harvesting stage of main crops. Numbers within white bars indicate the percentage of main crop DW to total DW. Vertical bars indicate standard error of total DW (n=4).

Fig. 4 Vegetation cover ratio (VCR) in the experiment for soybean in 2005 (a-d) and for maize in 2006 (e-h). (a, e) Sole-MC; (b, f) Pre-MC; (c, g) Syn-MC; (d, h) Post-MC. White area, main crops; Gray area, cover crops; Black area, weeds. Arrows indicate the sowing date of cover crops.

Fig. 5 Vegetation cover ratio (VCR) of main crops plus cover crops for soybean in 2005 (a) and maize in 2006 (b) on the basis of the accumulated effective temperature for dominant weed, redroot pigweed. The 
accumulated effective temperature for redroot pigweed was calculated as sum of dairy average temperature minus lower threshold temperature $\left(10.0{ }^{\circ} \mathrm{C}\right)$ of redroot pigweed for germination (Wiese and Binning, 1987). $\diamond$ Sole-MC; $\bigcirc$ Pre-MC; $\triangle$ Syn-MC; $\square$ Post-MC. Vertical bars indicate standard error $(\mathrm{n}=4)$.

Fig. 6 Leaf area index (LAI) and photosynthetically active radiation (PAR) transmittance at each height ath the maximum plant height stage of the main crops for soybean (76 DAS) in 2005 (a-d) and maize (77 DAS) in 2006 (e-h). (a, e) Sole-MC; (b, f) Pre-MC; (c, g) Syn-MC; (d, h) Post-MC. White bar, main crops; Gray bar, cover crops; Black bar, weeds. Open circle and solid line, PAR transmittance. LAI of cover crops at the bottom layer in (b) and (c) exceed the x-axis range and their values are 6.81 and 2.72, respectively.

Fig. 7 SPAD value of soybean in 2005 (a) and maize in 2006 (b). $\diamond$ Sole-MC; $\bigcirc$ Pre-MC; $\triangle$ Syn-MC;

Post-MC. Vertical bars indicate LSD values $(\mathrm{P}=0.05)$ for the comparison between treatments. The SPAD value in Pre-MC could not be measured after 64 days after planting main crops because the maize plants died.

Fig. 8 The relationship of the vegetation cover ratio (VCR) of main crops plus cover crops at $150{ }^{\circ} \mathrm{C} \cdot$ day of accumulated sufficient temperature for redroot pigweed with weed dry weight (DW) at the harvest stage of main crops. Black symbol, soybean in 2005; White symbol, maize in 2006; $\diamond$ Sole-MC; $\bigcirc$ Pre-MC; $\triangle$ Syn-MC; $\square$ Post-MC. *** Significant at $0.1 \%$ levels of probability. 

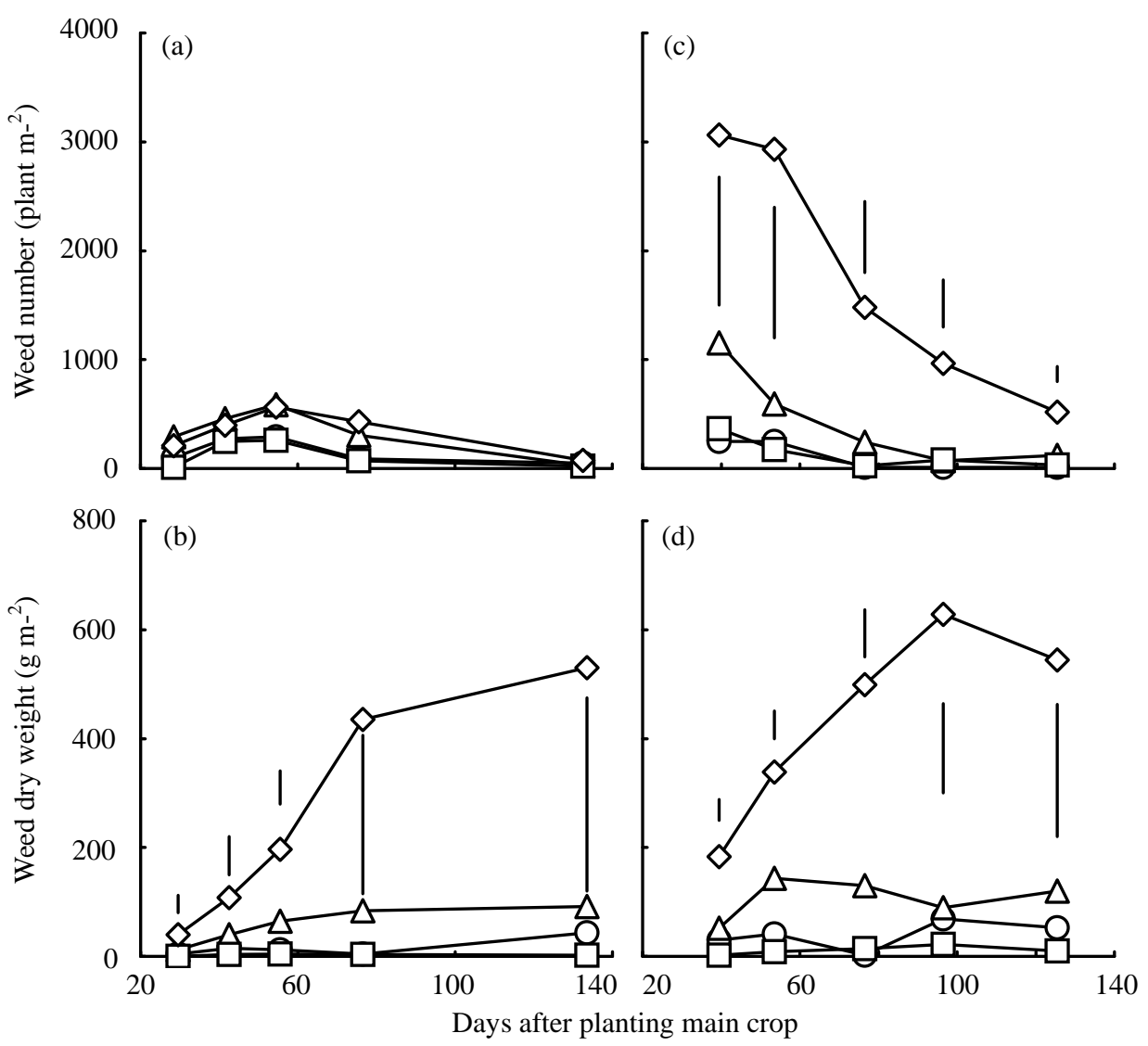

Fig. 1 Weed number (a, c) and weed dry weight (b, d) in the experiment for soybean in 2005 (a, b) and for maize in 2006 (c, d).

$\diamond$ Sole-MC; $\bigcirc$ Pre-MC; $\triangle$ Syn-MC; $\square$ Post-MC. Vertical bars indicate LSD values (P = 0.05) for the comparison between treatments. 


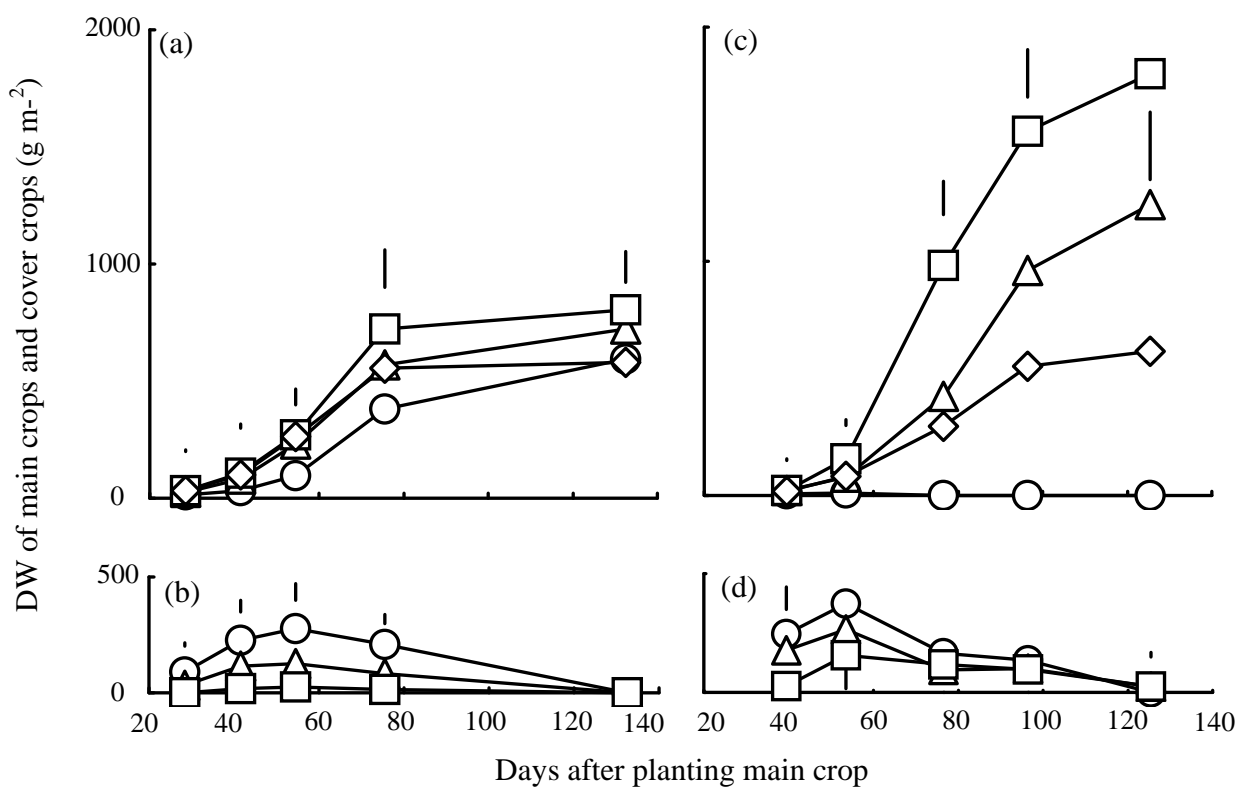

Fig. 2 Dry weight (DW) of soybean (a) and winter rye (b) in 2005, and maize (c) and hairy vetch (d) in 2006.

$\diamond$ Sole-MC; $\bigcirc$ Pre-MC; $\triangle$ Syn-MC; $\square$ Post-MC. Vertical bars indicate LSD values (P = 0.05) for the comparison between treatments. 

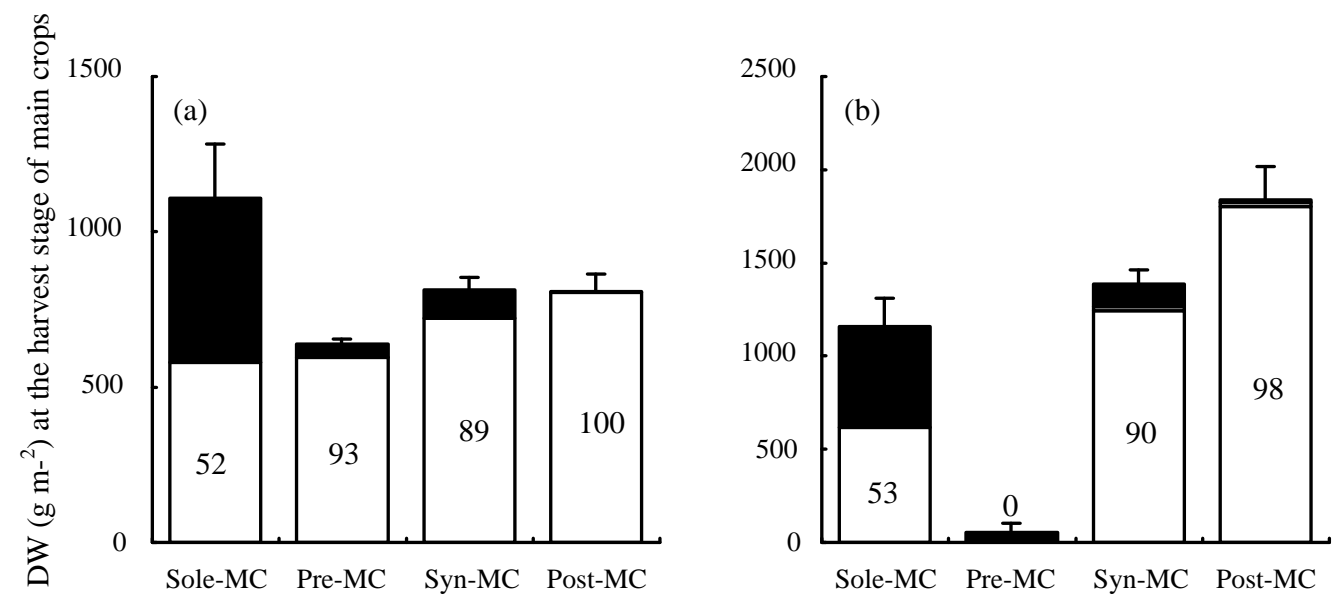

Fig. 3 Total dry weight (DW) of main crops and weeds at the harvest stage of soybean in 2005 (a) and maize in 2006 (b).

White bar, main crops; Black bar, weeds. Cover crops were dead completely at the harvesting stage of main crops. Numbers within white bars indicate the percentage of main crop DW to total DW. Vertical bars indicate standard error of total DW $(n=4)$. 


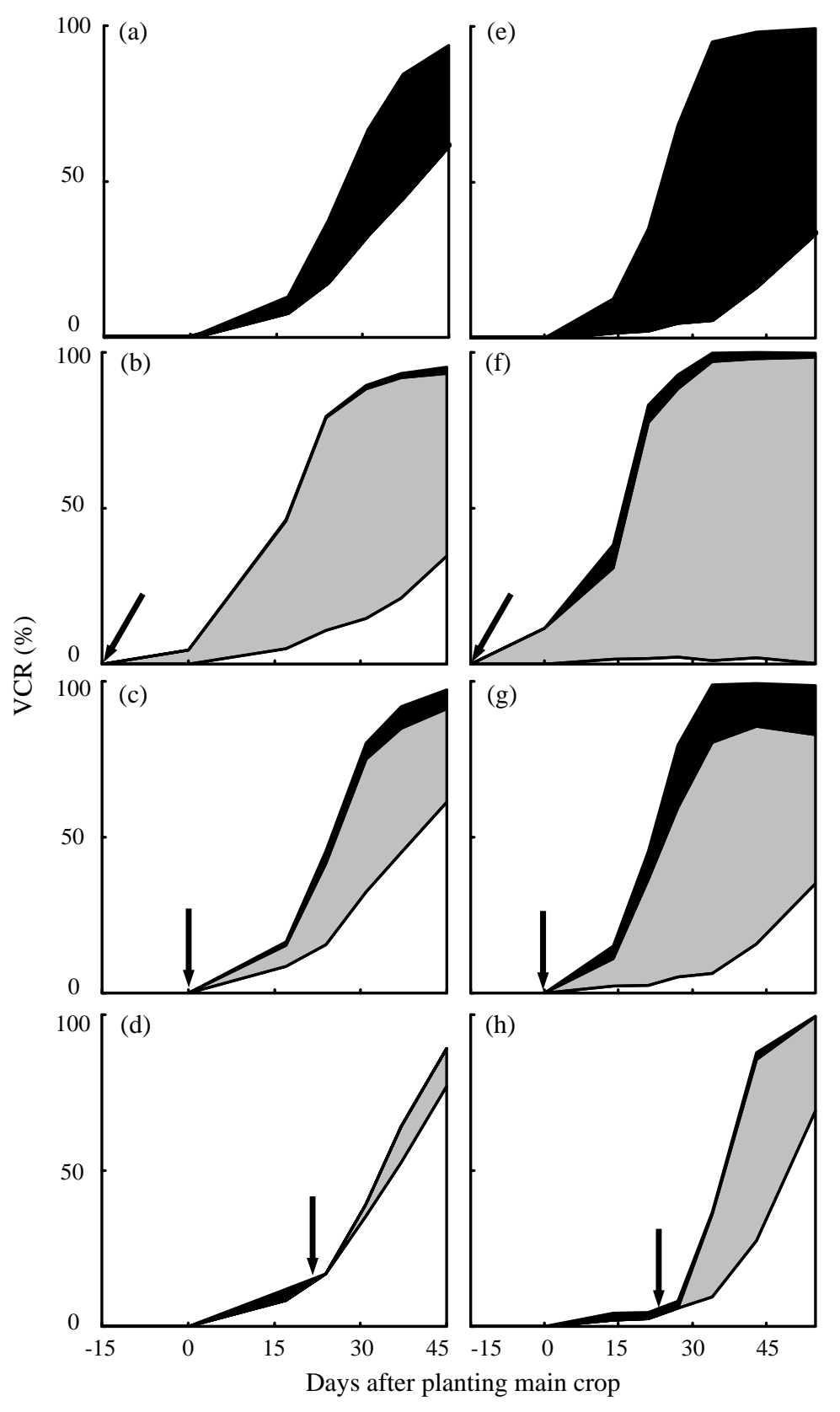

Fig. 4 Vegetation cover ratio (VCR) in the experiment for soybean in 2005 (a-d) and for maize in 2006 (e-h). (a, e) Sole-MC; (b, f) Pre-MC; (c, g) Syn-MC; (d, h) Post-MC. White area, main crops; Gray area, cover crops; Black area, weeds. Arrows indicate the sowing date of cover crops. 

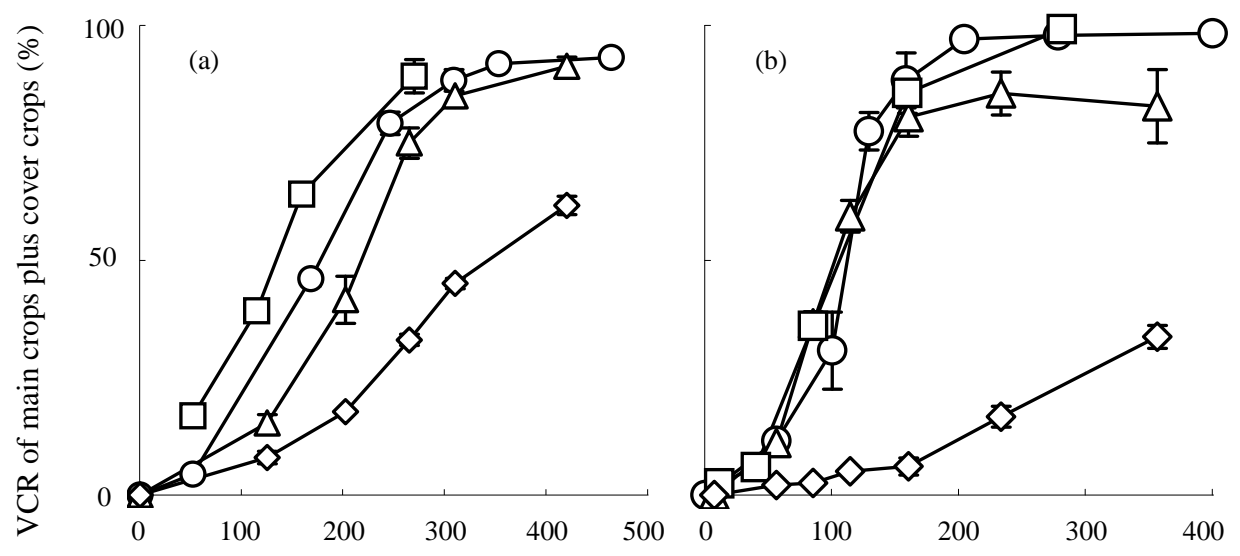

Accumulated effective temperature for redroot pigweed $\left({ }^{\circ} \mathrm{C} \cdot\right.$ day $)$

Fig. 5 Vegetation cover ratio (VCR) of main crops plus cover crops for soybean in 2005 (a) and maize in 2006 (b) on the basis of the accumulated effective temperature for dominant weed, redroot pigweed. The accumulated effective temperature for redroot pigweed was calculated as sum of dairy average temperature minus lower threshold temperature $\left(10.0{ }^{\circ} \mathrm{C}\right)$ of redroot pigweed for germination (Wiese and Binning, 1987). $\diamond$ Sole-MC; $\bigcirc$ Pre-MC; $\triangle$ Syn-MC; $\square$ Post-MC. Vertical bars indicate standard error $(n=4)$. 


\section{LAI}

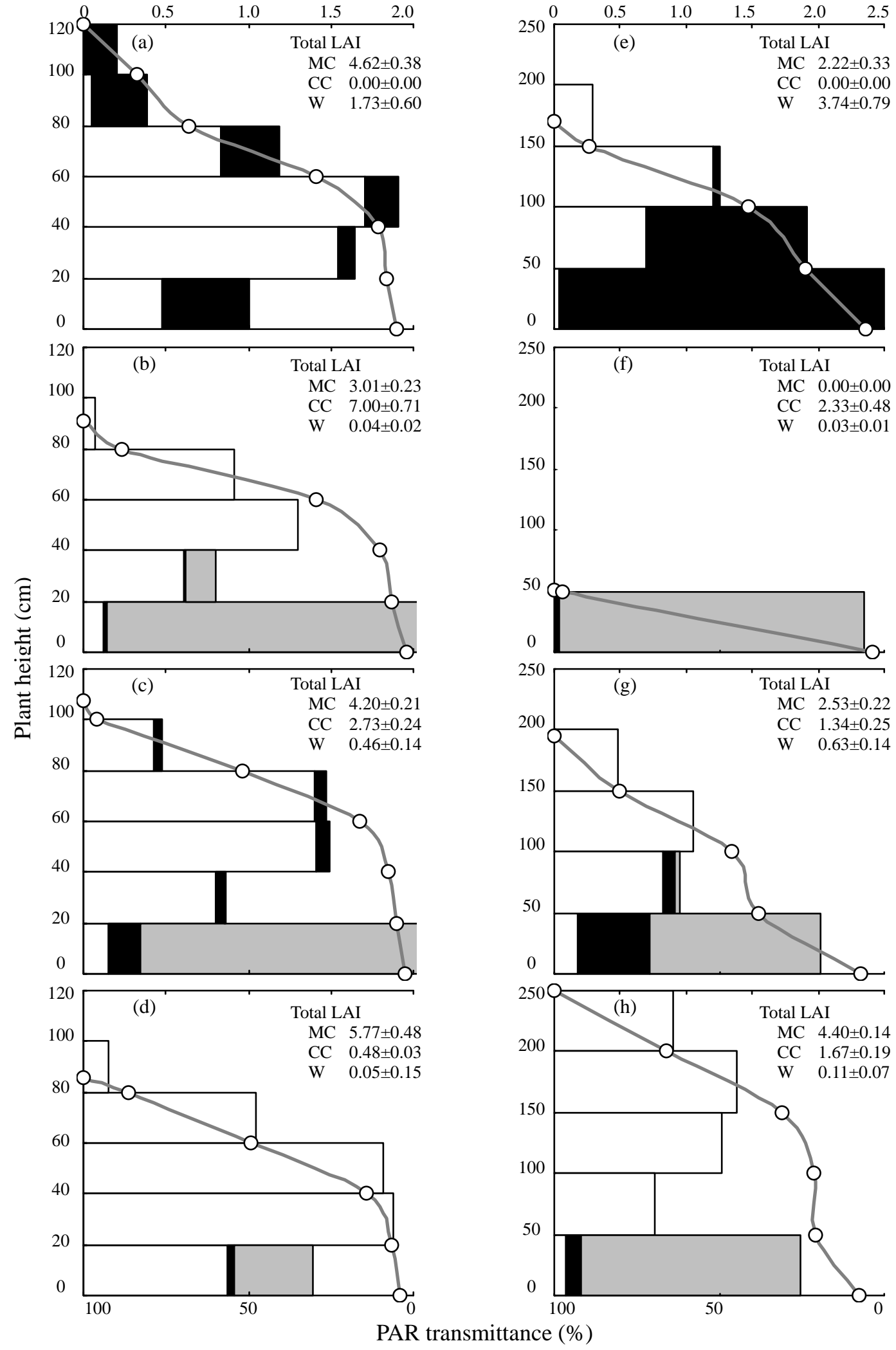

Fig. 6 Leaf area index (LAI) and photosynthetically active radiation (PAR) transmittance at each height ath the maximum plant height stage of the main crops for soybean (76 DAS) in 2005 (a-d) and maize (77 DAS) in 2006 (e-h). (a, e) Sole-MC; (b, f) Pre-MC; (c, g) Syn-MC; (d, h) Post-MC. White bar, main crops; Gray bar, cover crops; Black bar, weeds. Open circle and solid line, PAR transmittance. LAI of cover crops at the bottom layer in (b) and (c) exceed the x-axis range and their values are 6.81 and 2.72, respectively. 


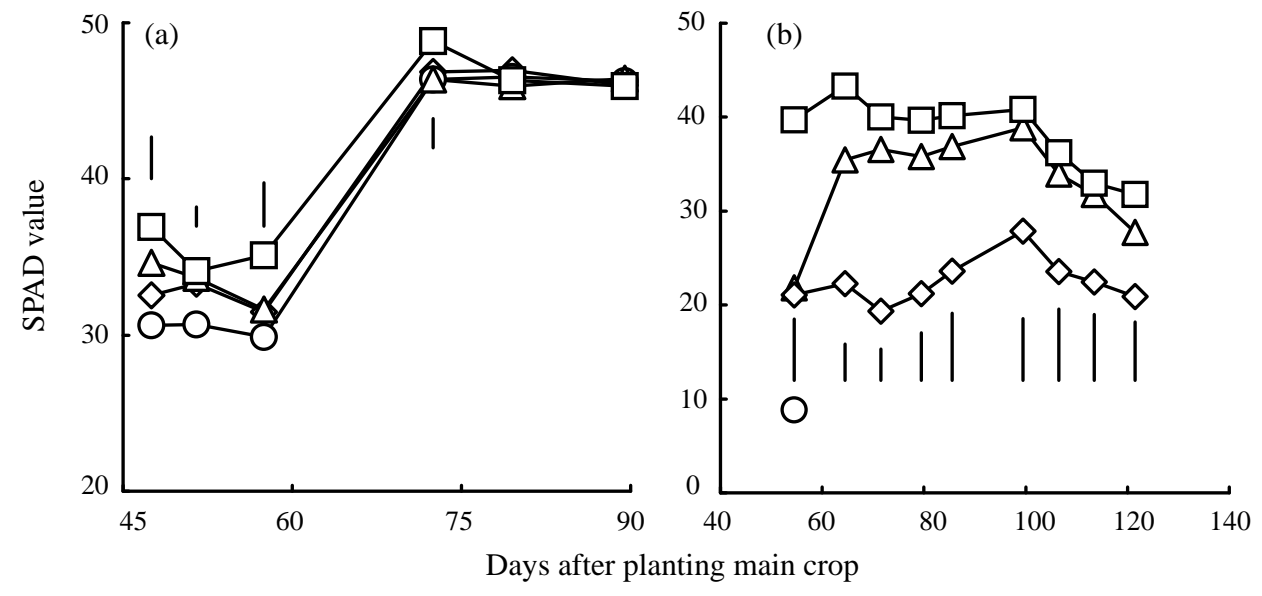

Fig. 7 SPAD value of soybean in 2005 (a) and maize in 2006 (b). $\diamond$ Sole-MC; $\bigcirc$ Pre-MC; $\triangle$ Syn-MC; $\square$ Post-MC. Vertical bars indicate LSD values $(\mathrm{P}=0.05)$ for the comparison between treatments. The SPAD value in Pre-MC could not be measured after 64 days after planting main crops because the maize plants died. 


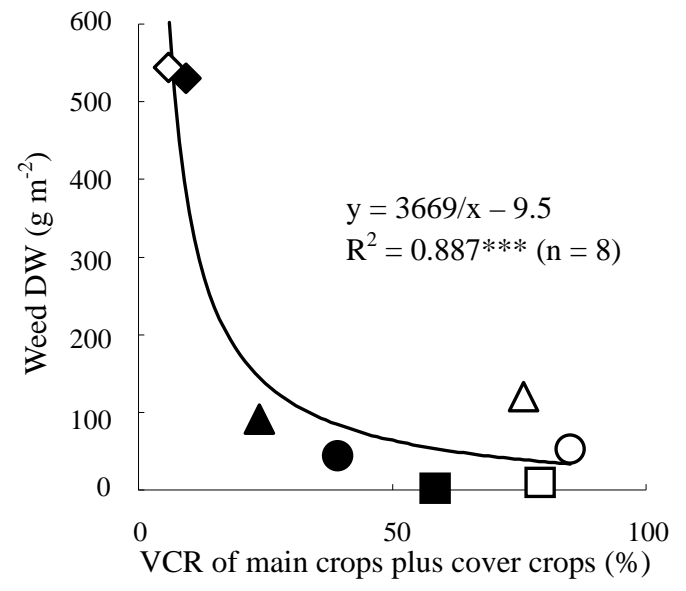

Fig. 8 The relationship of the vegetation cover ratio (VCR) of main crops plus cover crops at 150 ${ }^{\circ} \mathrm{C}$-day of accumulated sufficient temperature for redroot pigweed with weed dry weight (DW) at the harvest stage of main crops. Black symbol, soybean in 2005; White symbol, maize in 2006; $\diamond$ Sole-MC; $\bigcirc$ Pre-MC; $\triangle$ Syn-MC; $\square$ Post-MC. *** Significant at $0.1 \%$ levels of probability. 